\title{
Second-line Treatment of Non-Small Cell Lung Cancer: Focus on the Clinical Development of Dacomitinib
}

\author{
Jon Zugazagoitia ${ }^{1}$, Asunción Díaz ${ }^{1}$, Elisabeth Jimenez ${ }^{1}$, Juan Antonio Nuñez ${ }^{1}$, \\ Lara Iglesias ${ }^{1}$, Santiago Ponce-Aix ${ }^{1}$ and Luis Paz-Ares ${ }^{1,2 *}$ \\ ${ }^{1}$ Medical Oncology Department, Hospital Universitario 12 de Octubre, Instituto de Investigación i+12, Madrid, Spain, \\ ${ }^{2}$ Complutense University, Madrid, Spain
}

OPEN ACCESS

Edited by:

Umberto Malapelle,

University of Naples

Federico II, Italy

Reviewed by:

Dario De Biase,

University of Bologna, Italy Luca Toschi,

Humanitas Research Hospital, Italy

*Correspondence: Luis Paz-Ares

Ipazaresr@seom.org

Specialty section:

This article was submitted to Pathology,

a section of the journal

Frontiers in Medicine

Received: 28 February 2017 Accepted: 17 March 2017

Published: 05 April 2017

Citation:

Zugazagoitia J, Díaz A, Jimenez E, Nuñez JA, Iglesias L, Ponce-Aix S and Paz-Ares L (2017) Second-line

Treatment of Non-Small Cell Lung Cancer: Focus on the Clinical Development of Dacomitinib.

Front. Med. 4:36.

doi: 10.3389/fmed.2017.00036
Dacomitinib is a second-generation, irreversible, covalent pan-HER tyrosine-kinase inhibitor (TKI). It showed potent EGFR signaling inhibition in experimental models, including first-generation TKI-resistant non-small cell lung cancer (NSCLC) cell lines. This preclinical efficacy did not translate into clinically meaningful treatment benefits for advanced, pretreated, molecularly unselected NSCLC patients enrolled in two parallel phase III trials. Dacomitinib and erlotinib showed overlapping efficacy data in chemotherapy-pretreated EGFR wild-type (WT) patients in the ARCHER 1009 trial. Similarly, it failed to demonstrate any survival benefits as compared to placebo in EGFR WT subsets progressing on chemotherapy and at least one previous first-generation TKI (erlotinib or gefitinib) in the BR.26 trial. In the case of EGFR-mutant NSCLCs, a pooled analysis of the ARCHER 1009 and ARCHER 1028 trials comparing the efficacy of dacomitinib vs. erlotinib in chemotherapy-pretreated, EGFR TKI-naïve patients showed a trend to a longer progression-free survival (PFS) and overall survival in favor of dacomitinib that did not reach statistical significance, with a higher rate of treatment related adverse events (mainly skin rash, paronychia, and gastrointestinal toxicities). On the other hand, the clinical activity in patients with EGFR-mutant NSCLCs with acquired TKI resistance that were included in phase II/III trials was equally poor (response rate $<10 \%$; PFS 3-4 months). Therefore, with the results of the ARCHER 1050 trial (NCT01774721) still pending, the current clinical development of dacomitinib is largely focused on EGFR-mutant, TKI-naïve patients. Here, we review the most relevant clinical data of dacomitinib in advanced NSCLC. We discuss the potential role of dacomitinib in pretreated EGFR WT and EGFR-mutant (TKI-naïve and TKI-resistant) patients. Finally, we briefly comment the available clinical data of dacomitinib in HER2-mutant NSCLC patients.

Keywords: non-small cell lung cancer, second-line treatment, EGFR mutations, second-generation EGFR tyrosinekinase inhibitors, dacomitinib, acquired resistance

\section{INTRODUCTION}

Second-line treatment options for advanced non-small cell lung cancer (NSCLC) patients have substantially expanded in the past few years. Docetaxel- or pemetrexed-based chemotherapy and erlotinib were the only three drugs approved in our setting until year 2014, achieving an approximate $8-10 \%$ of response rates (RRs), median 4 months of progression-free survival (PFS) and 8-10 months of overall survival (OS) (1). Recently, antiangiogenics [ramucirumab (2), nintedanib (3), and bevacizumab (4)] and particularly PD-1/PD-L1 inhibitors [nivolumab $(5,6)$, pembrolizumab (7), and atezolizumab (8)] 
have shown to prolong survival in pretreated patients, transforming the standardization of second-line NSCLC treatment.

In the absence of significant differences in terms of efficacy, the choice between pemetrexed- or docetaxel-based second-line chemotherapy is largely driven by three factors: histology, as pemetrexed is restricted to non-squamous tumors, type of platinum doublet used during first-line treatment, with pemetrexed being increasingly incorporated into the first-line or maintenance treatments, and differences in toxicity profiles. On the other hand, when deciding between chemotherapy and erlotinib, apart from clinical factors, EGFR mutation status is the main biomarker that determines treatment selection.

The IPASS trial definitely demonstrated that the clinical activity of EGFR tyrosine-kinase inhibitors (TKIs) in treatment-naïve patients was restricted to those with EGFR-mutant tumors (EGFR-sensitizing mutations). As the clinical activity of EGFR TKIs in TKI-naïve, EGFR-mutant tumors is comparable between treatment-naïve or platinum-pretreated patients (9), first- or second-generation EGFR TKIs are the preferred treatment options in patients with EGFR-mutant tumors. On the contrary, in patients with EGFR wild-type (WT) cancers, RRs and survival were significantly lower with gefitinib- compared to platinum-based chemotherapy in the IPASS study (10). However, whether this was also true in the second-line setting, a clinical context in which the efficacy of docetaxel- or pemetrexed-based chemotherapy hardly reaches $10 \%$ of RRs, has been a matter of extensive debate in the past few years. Some molecularly unselected randomized trials, initiated at a time where no definitive predictive biomarkers for the benefit or EGFR TKIs were discovered yet, initially suggested similar efficacy outcomes between erlotinib and second-line chemotherapy (11-13). More recent data, including molecularly selected or molecularly stratified randomized trials and large meta-analysis, have confirmed that second-line chemotherapy is superior to EGFR TKIs in patients with EGFR WT tumors, at least in terms of RRs and PFS. OS differences did not reach statistical significance (14-16).

In this therapeutic scenario, and considering that EGFR pathway activation might hypothetically contribute to cancer progression even in tumors with no EGFR activating mutations (17), to investigate if a more potent pan-HER inhibition with dacomitinib would add any clinical benefit seemed a rational approach, either from a biological or a clinical perspective. In addition, as the majority of patients with EGFR-mutant tumors treated with first-generation EGFR TKIs develop acquired resistance by ERBB-dependent mechanisms (18), and considering that dacomitinib showed activity in gefitinib-resistant preclinical lung cancer models (19), it was also rational to test its clinical activity in patients with EGFRmutant, TKI-resistant cancers. Herein, we will succinctly discuss the potential role of second-line dacomitinib in EGFR WT and EGFR-mutant NSCLC.

\section{DACOMITINIB: PRECLINICAL AND EARLY CLINICAL DATA IN NSCLC}

Dacomitinib is a second-generation, irreversible, covalentbinding pan-HER TKI. As compared to first-generation EGFR TKIs, it has comparable inhibitory activity against the WT EGFR kinase in vitro. However, dacomitinib is more potent than gefitinib against cell lines harboring common EGFR-sensitizing mutations (del19, L858R). Moreover, it has inhibitory activity against gefitinib-resistant exon 20 insertions and acquired resistance exon 20 T790M mutations in preclinical lung cancer models. Unlike gefitinib or other first-generation TKIs, dacomitinib, as a pan-ERBB inhibitor, also inhibits the activity of both WT and mutant HER2 kinase $(19,20)$.

Three phase I trials, conducted both in Western and Asian patients, established that the maximum tolerated dose of dacomitinib was $45 \mathrm{mg}$ daily, and this dose level was selected for further clinical evaluation. The most frequent dose-limiting drug-related adverse events were skin and gastrointestinal toxicities (21-23). The three trials consistently demonstrated that plasma concentrations and other pharmacokinetic parameters proportionally increased with increasing doses of oral dacomitinib (21-23), with no apparent food effect (21). Dacomitinib's half-life was estimated at $59-85 \mathrm{~h}$ in the phase I trial conducted in the United States (21). A modest preliminary clinical activity was observed in small cohorts of NSCLC patients previously treated with first-generation EGFR TKIs and/or chemotherapy. No objective responses were seen in EGFR TKI-resistant patients whose tumors harbored EGFR T790M mutations (21-23).

\section{DACOMITINIB FOR PRETREATED NSCLC PATIENTS}

\section{Clinical Data in EGFR WT or NSCLCs Unselected by EGFR Status}

The clinical activity of dacomitinib in pretreated NSCLC patients has been evaluated in four clinical trials (24-27). They are mostly molecularly unselected trials and, consequently, the vast majority of the patients included had EGFR WT tumors. An overview of the four clinical trials and the efficacy data in the overall study population are summarized in Table $\mathbf{1}$.

Two phase II trials initially suggested some degree of clinical activity in pretreated NSCLC patients. The ARCHER 1002 trial was a single-arm study that tested the activity of dacomitinib in patients that were refractory to one or two lines of chemotherapy and erlotinib. On the basis that KRAS mutant cell lines were primarily resistant to first- or second-generation EGFR TKIs, this study was enriched with patients with KRAS WT tumors. The trial failed to meet its primary end point, as dacomitinib yielded a disappointing 5.2 and $4.8 \%$ of RRs in the overall and adenocarcinoma subsets, respectively. Patients with EGFR WT/KRAS WT tumors included in this trial had comparable RRs (5\%), PFS (8 weeks), and OS (26 weeks) to those of the overall study population (25) (Table 1). The second phase II trial (ARCHER 1028) compared the activity of dacomitinib and erlotinib in molecularly unselected patients progressing on one or two prior chemotherapy regimens. In this case, the trial met its primary endpoint, showing a statistically significant increase in PFS (2.86 vs. 1.91 months, HR 0.66, CI 95\% 0.47-0.91) in favor of dacomitinib in the overall study population. Objective responses were also higher in dacomitinib treated patients (17 vs. $5.3 \%, p=0.01$ ). However, no differences in OS were noted (HR 0.80, CI 95\% 0.56-1.10, $p=0.20$ ) (Table 1). Comparable degree of PFS increment to the overall population was observed in EGFR WT NSCLCs (HR 0.70, CI 95\% 0.47-1.05) and EGFR WT/KRAS 


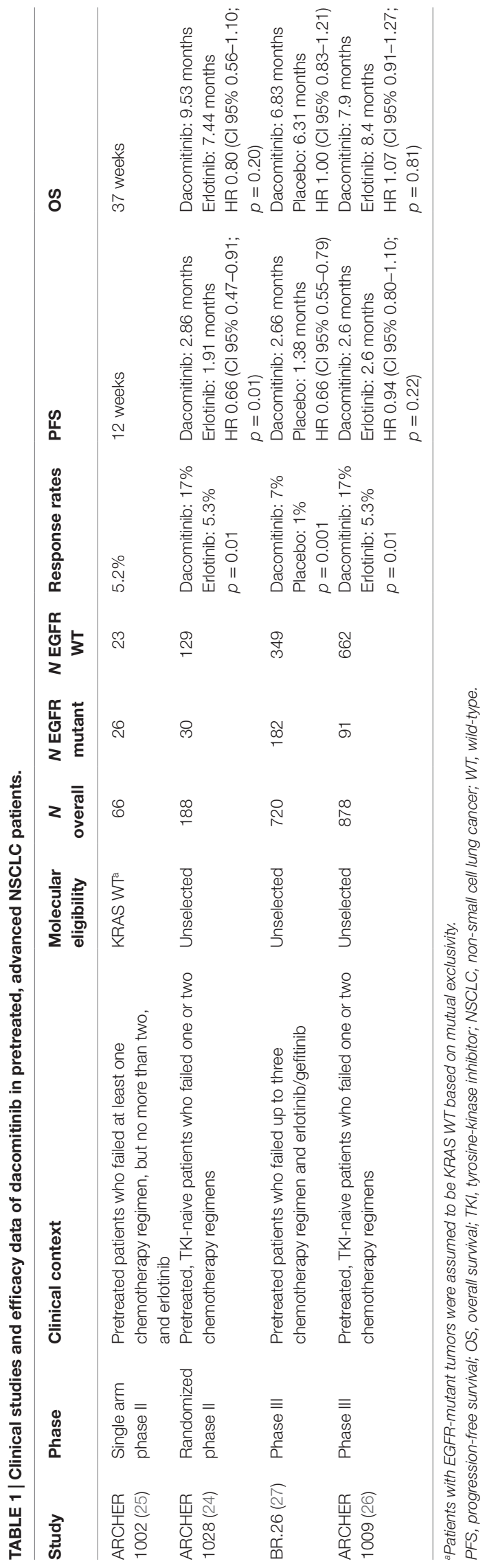

WT NSCLCs (HR 0.61, CI 95\% 0.37-0.99). Dacomitinib did not improve OS compared to erlotinib in patients with EGFR WT cancers (24).

This modest clinical activity served as the basis to launch two subsequent randomized phase III trials in similar therapeutic scenarios to their respective phase II trials. Unfortunately, both phase III studies were negative. First, in the BR.26 trial, whereas dacomitinib statistically significantly improved RRs ( 7 vs. $1 \%, p=0.001$ ) and PFS (2.66 vs. 1.38 months, HR $0.66 \mathrm{CI}$ 95\% 0.55-0.79) compared to placebo in patients progressing on chemotherapy and EGFR TKIs, it failed to demonstrate improved OS (primary end point; HR 1.00) (Table 1). Similarly, no trend for a clinically meaningful incremental efficacy was observed in patients with EGFR WT tumors or patients with both EGFR and KRAS WT NSCLCs compared to the overall patient population (27). And finally, Dacomitinib failed to improve the efficacy of erlotinib (control arm) in second- or third-line settings (ARCHER 1009), either in the overall population (Table 1) or in patients with EGFR WT tumors. In the latter subgroup, dacomitinib had overlapping objective RRs, PFS (1.9 vs. 1.9 months; HR 0.94, CI $95 \% 0.79-1.13$ ), and OS (6.8 vs. 7.6 months; HR 1.07, CI 95\% 0.90-1.29) compared to erlotinib. Results were almost identical for patients with either KRAS or EGFR WT NSCLCs (26).

\section{Clinical Data in EGFR-Mutant, TKI-Naïve NSCLCs}

In the particular case of pretreated, TKI-naïve subsets, a pooled analysis of the ARCHER 1009 and ARCHER 1028 trials comparing the efficacy of dacomitinib vs. erlotinib showed a comparable median PFS (14.6 vs. 9.6 months, respectively; HR $0.71, p=0.14$ ) and OS (26.6 vs. 23.2 months, respectively; HR $0.73, p=0.26$ ) outcomes that somehow favored dacomitinib (28) (Table 2). Both ARCHER 1028 and ARCHER 1009 trials showed that on target adverse events related to the inhibition of EGFR WT in normal tissues were significantly increased with dacomitinib compared to erlotinib, mainly skin rash, paronychia, and gastrointestinal toxicities $(24,26)$. These data are in line with the recently published LUX-Lung 7 trial, where afatinib significantly delayed PFS and the emergence of EGFR TKI resistance, albeit with a higher incidence of treatment related adverse events (29).

\section{Clinical Data in EGFR-Mutant, TKI-Pretreated NSCLCs}

In the context of EGFR TKI acquired resistance, the clinical efficacy of dacomitinib in patients with EGFR-mutant lung cancers progressing on first-generation EGFR TKIs that were included in these trials was disappointingly low, with an overall RR of about $8 \%$ (Table 2). No objective responses were reported among patients whose tumors harbored the secondary acquired resistance EGFR T790M mutation. In general, the PFS and OS data did not differ to those of the unselected patient population either $(25,27)$.

\section{Clinical Data in HER2-Mutant, TKI-Naïve NSCLCs}

In the largest prospective phase II study conducted to date in patients with HER2-mutant or HER2-amplified tumors $(n=30$; 
TABLE 2 | Clinical data of dacomitinib in EGFR-mutant NSCLCs.

\begin{tabular}{|c|c|c|c|c|c|c|}
\hline Study & Phase & Clinical context & $\begin{array}{l}\text { No. of patients with } \\
\text { EGFR-mutant tumors } \\
\text { (sensitizing mutations) }\end{array}$ & Response rates (\%) & PFS & OS \\
\hline A7471017 (30) & $\|$ & Treatment naive & 45 & 76 & 18.2 months & - \\
\hline $\begin{array}{l}\text { Pooled analysis ARCHER } 1009 \\
\text { and ARCHER } 1028 \text { (28) }\end{array}$ & II and III & $\begin{array}{l}\text { Chemotherapy-pretreated, } \\
\text { TKI naive }\end{array}$ & 101 & 67.9 & 14.6 months & 26.6 months \\
\hline ARCHER 1002 (25) & $\|$ & TKI resistant & 24 & 8 & 18 weeks & 56 weeks \\
\hline BR.26 (27) & III & TKI resistant & 114 & - & 3.52 months & 7.23 months \\
\hline
\end{tabular}

PFS, progression-free survival; OS, overall survival; TKI, tyrosine-kinase inhibitor; NSCLCs, non-small cell lung cancers.

$83 \%$ had received at least one line of previous chemotherapy), dacomitinib showed only modest efficacy, with an objective RR of $12 \%, 3$ months of median PFS, and 9 months of median OS. No responses were seen in patients with tumors harboring the most common HER2 activating mutation (c. 2324_2325ins12) (31). Intriguingly, tumors with this genotype did respond to afatinib in other series (32). No responses were seen either in patients with HER2-amplified cancers $(n=4)(31)$. More studies are needed in order to determine which molecular contextures (i.e., possible coexistence with HER2 amplification) and what specific HER2 genotypes are true predictive targets for the benefit of dacomitinib.

\section{CONCLUSION AND FUTURE PERSPECTIVES}

Dacomitinib has failed to improve overall outcomes in pretreated NSCLC patients. An irreversible pan-HER inhibition is not superior to erlotinib in patients with no EGFR-sensitizing mutations and does not prolong OS compared to placebo in heavily pretreated patients either. Also, dacomitinib does not overcome EGFR T790M-mediated acquired resistance in EGFR-mutant NSCLCs at tolerable doses in humans. In non-T790M-mediated resistance, in which functional activation of HER pathway or acquired HER 2 activating mutations have been described in some cases $(18,33)$, no reliable clinical data are available, but a robust activity in this clinical setting seems unlikely. With these clinical data, together with recent regulatory approvals of third-generation, EGFR-mutant selective TKIs (e.g., osimertinib) with potent activity against the T790M mutation (34), current development of dacomitinib is focused to TKI treatment-naïve, molecularly selected

\section{REFERENCES}

1. Weiss JM, Stinchcombe TE. Second-line therapy for advanced NSCLC. Oncologist (2013) 18(8):947-53. doi:10.1634/theoncologist.2013-0096

2. Garon EB, Ciuleanu T-E, Arrieta O, Prabhash K, Syrigos KN, Goksel T, et al. Ramucirumab plus docetaxel versus placebo plus docetaxel for second-line treatment of stage IV non-small-cell lung cancer after disease progression on platinum-based therapy (REVEL): a multicentre, double-blind, randomised phase 3 trial. Lancet (2014) 384(9944):665-73. doi:10.1016/S0140-6736(14)60845-X

3. Reck M, Kaiser R, Mellemgaard A, Douillard J-Y, Orlov S, Krzakowski M, et al. Docetaxel plus nintedanib versus docetaxel plus placebo in patients with previously treated non-small-cell lung cancer (LUME-Lung 1): a phase 3, double-blind, randomised controlled trial. Lancet Oncol (2014) 15(2):143-55. doi:10.1016/S1470-2045(13)70586-2

4. Cortot AB, Audigier-Valette C, Molinier O, Le Moulec S, Barlesi F, Zalcman G, et al. Weekly paclitaxel plus bevacizumab versus docetaxel as second or patients with EGFR-mutant and HER2-mutant lung cancers. In a small phase II trial including a total of 45 treatment-naïve patients with tumors harboring common EGFR-sensitizing mutations, dacomitinib achieved an overall RR of $75.6 \%$ and a median PFS of 18.2 months (30).

In this regard, whether second-generation EGFR TKIs in TKI-naive patients are superior to first-generation TKIs in EGFRmutant NSCLCs is not fully answered to date. In the LUX-Lung 7 trial, afatinib significantly increased RRs (70 vs. 56\%; $p=0.0083$ ), median PFS (11 vs. 10.9 months; HR 0.73, CI 95\% 0.57-0.95; $p=0.0195$ ), and median time to treatment failure (13.7 vs. 11.5 months; HR 0.73, CI 95\% 0.58-0.92; $p=0.0073$ ) over gefinitib. However, there were no OS differences among treatment arms in this phase IIb trial $(n=319)$. Pre-specified subgroup analysis according to mutation type (exon 19 deletions vs. L858R mutations) did no show significant differences in OS either. Overall, treatment-related adverse events (mainly skin rash and diarrhea) and serious adverse events were more common with afatinib (33). Therefore, this trial suggests that the emergence of acquired resistance might be delayed with second-generation compared to first-generation TKIs, but whether these modest differences are clinically relevant for patients is arguable for many physicians. The ARCHER 1050 trial (NCT01774721) comparing first-line dacomitinb vs. gefitinib has recently completed accrual and will hopefully give a definitive answer in this regard, establishing the true role of front-line dacomitinib in EGFR-mutant NSCLCs.

\section{AUTHOR CONTRIBUTIONS}

All authors contributed equally to this work.

third-line treatment in advanced non-squamous non-small cell lung cancer (NSCLC): results from the phase III study IFCT-1103 ULTIMATE. J Clin Oncol (2016) 34(Suppl):abstr 9005.

5. Borghaei H, Paz-Ares L, Horn L, Spigel DR, Steins M, Ready NE, et al. Nivolumab versus docetaxel in advanced nonsquamous non-small-cell lung cancer. N Engl J Med (2015) 373(17):1627-39. doi:10.1056/NEJMoa1507643

6. Brahmer J, Reckamp KL, Baas P, Crinò L, Eberhardt WEE, Poddubskaya E, et al. Nivolumab versus docetaxel in advanced squamous-cell non-small-cell lung cancer. NEngl J Med (2015) 373(2):123-35. doi:10.1056/NEJMoa1504627

7. Herbst RS, Baas P, Kim D-W, Felip E, Perez-Gracia JL, Han J-Y, et al. Pembrolizumab versus docetaxel for previously treated, PD-L1-positive, advanced non-small-cell lung cancer (KEYNOTE-010): a randomised controlled trial. Lancet (2016) 387(10027):1540-50. doi:10.1016/S0140-6736(15)01281-7

8. Fehrenbacher L, Spira A, Ballinger M, Kowanetz M, Vansteenkiste J, Mazieres J, et al. Atezolizumab versus docetaxel for patients with previously treated non-small-cell lung cancer (POPLAR): a multicentre, open-label, phase 2 
randomised controlled trial. Lancet (2016) 387(10030):1837-46. doi:10.1016/ S0140-6736(16)00587-0

9. Mok T, Yang J-J, Lam K-C. Treating patients with EGFR-sensitizing mutations: first line or second line - is there a difference? J Clin Oncol (2013) 31(8):1081-8. doi:10.1200/JCO.2012.43.0652

10. Mok TS, Wu Y-L, Thongprasert S, Yang C-H, Chu DT, Saijo N, et al. Gefitinib or carboplatin-paclitaxel in pulmonary adenocarcinoma. N Engl J Med (2009) 361(10):947-57. doi:10.1056/NEJMoa0810699

11. Shepherd FA, Rodrigues Pereira J, Ciuleanu T, Tan EH, Hirsh V, Thongprasert $\mathrm{S}$, et al. Erlotinib in previously treated non-small-cell lung cancer. $N$ Engl J Med (2005) 353(2):123-32. doi:10.1056/NEJMoa050753

12. Ciuleanu T, Stelmakh L, Cicenas S, Miliauskas S, Grigorescu AC, Hillenbach C, et al. Efficacy and safety of erlotinib versus chemotherapy in second-line treatment of patients with advanced, non-small-cell lung cancer with poor prognosis (TITAN): a randomised multicentre, open-label, phase 3 study. Lancet Oncol (2012) 13(3):300-8. doi:10.1016/S1470-2045(11)70385-0

13. Karampeazis A, Voutsina A, Souglakos J, Kentepozidis N, Giassas S, Christofillakis C, et al. Pemetrexed versus erlotinib in pretreated patients with advanced non-small cell lung cancer: a Hellenic Oncology Research Group (HORG) randomized phase 3 study. Cancer (2013) 119(15):2754-64. doi:10.1002/cncr.28132

14. Garassino MC, Martelli O, Broggini M, Farina G, Veronese S, Rulli E, et al. Erlotinib versus docetaxel as second-line treatment of patients with advanced non-small-cell lung cancer and wild-type EGFR tumours (TAILOR): a randomised controlled trial. Lancet Oncol (2013) 14(10):981-8. doi:10.1016/ S1470-2045(13)70310-3

15. Kawaguchi T, Ando M, Asami K, Okano Y, Fukuda M, Nakagawa H, et al. Randomized phase III trial of erlotinib versus docetaxel as second- or thirdline therapy in patients with advanced non-small-cell lung cancer: docetaxel and erlotinib lung cancer trial (DELTA). J Clin Oncol (2014) 32(18):1902-8. doi:10.1200/JCO.2013.52.4694

16. Zhao N, Zhang X-C, Yan H-H, Yang J-J, Wu Y-L. Efficacy of epidermal growth factor receptor inhibitors versus chemotherapy as second-line treatment in advanced non-small-cell lung cancer with wild-type EGFR: a meta-analysis of randomized controlled clinical trials. Lung Cancer (2014) 85(1):66-73. doi:10.1016/j.lungcan.2014.03.026

17. Sordella R, Bell DW, Haber DA, Settleman J. Gefitinib-sensitizing EGFR mutations in lung cancer activate anti-apoptotic pathways. Science (2004) 305(5687):1163-7. doi:10.1126/science.1101637

18. Camidge DR, Pao W, Sequist LV. Acquired resistance to TKIs in solid tumours: learning from lung cancer. Nat Rev Clin Oncol (2014) 11(8):473-81. doi:10.1038/nrclinonc.2014.104

19. Engelman JA, Zejnullahu K, Gale C-M, Lifshits E, Gonzales AJ, Shimamura T, et al. PF00299804, an irreversible pan-ERBB inhibitor, is effective in lung cancer models with EGFR and ERBB2 mutations that are resistant to gefitinib. Cancer Res (2007) 67(24):11924-32. doi:10.1158/0008-5472.CAN$07-1885$

20. Gonzales AJ, Hook KE, Althaus IW, Ellis PA, Trachet E, Delaney AM, et al. Antitumor activity and pharmacokinetic properties of PF-00299804, a second-generation irreversible pan-erbB receptor tyrosine kinase inhibitor. Mol Cancer Ther (2008) 7(7):1880-9. doi:10.1158/1535-7163.MCT07-2232

21. Jänne PA, Boss DS, Camidge DR, Britten CD, Engelman JA, Garon EB, et al. Phase I dose-escalation study of the pan-HER inhibitor, PF299804, in patients with advanced malignant solid tumors. Clin Cancer Res (2011) 17(5):1131-9. doi:10.1158/1078-0432.CCR-10-1220

22. Takahashi T, Boku N, Murakami H, Naito T, Tsuya A, Nakamura Y, et al. Phase I and pharmacokinetic study of dacomitinib (PF-00299804), an oral irreversible, small molecule inhibitor of human epidermal growth factor receptor- $1,-2$, and -4 tyrosine kinases, in Japanese patients with advanced solid tumors. Invest New Drugs (2012) 30(6):2352-63. doi:10.1007/s10637-011-9789-z

23. Park K, Cho BC, Kim D-W, Ahn M-J, Lee S-Y, Gernhardt D, et al. Safety and efficacy of dacomitinib in Korean patients with KRAS wild-type advanced non-small-cell lung cancer refractory to chemotherapy and erlotinib or gefitinib: a phase I/II trial. J Thorac Oncol (2014) 9(10):1523-31. doi:10.1097/ JTO.0000000000000275

24. Ramalingam SS, Blackhall F, Krzakowski M, Barrios CH, Park K, Bover I, et al. Randomized phase II study of dacomitinib (PF-00299804), an irreversible pan-human epidermal growth factor receptor inhibitor, versus erlotinib in patients with advanced non-small-cell lung cancer. JClin Oncol (2012) 30(27):3337-44. doi:10.1200/JCO.2011.40.9433

25. Reckamp KL, Giaccone G, Camidge DR, Gadgeel SM, Khuri FR, Engelman JA, et al. A phase 2 trial of dacomitinib (PF-00299804), an oral, irreversible panHER (human epidermal growth factor receptor) inhibitor, in patients with advanced non-small cell lung cancer after failure of prior chemotherapy and erlotinib. Cancer (2014) 120(8):1145-54. doi:10.1002/cncr.28561

26. Ramalingam SS, Jänne PA, Mok T, O’Byrne K, Boyer MJ, Pawel von J, et al. Dacomitinib versus erlotinib in patients with advanced-stage, previously treated non-small-cell lung cancer (ARCHER 1009): a randomised, double-blind, phase 3 trial. Lancet Oncol (2014) 15(12):1369-78. doi:10.1016/ S1470-2045(14)70452-8

27. Ellis PM, Shepherd FA, Millward M, Perrone F, Seymour L, Liu G, et al. Dacomitinib compared with placebo in pretreated patients with advanced or metastatic non-small-cell lung cancer (NCIC CTG BR.26): a double-blind, randomised, phase 3 trial. Lancet Oncol (2014) 15(12):1379-88. doi:10.1016/ S1470-2045(14)70472-3

28. Ramalingam SS, O'Byrne K, Boyer M, Mok T, Janne PA, Zhang H, et al. Dacomitinib versus erlotinib in patients with EGFR-mutated advanced nonsmall-cell lung cancer (NSCLC): pooled subset analyses from two radomized trials. Ann Oncol (2016) 27(7):1363. doi:10.1093/annonc/mdw221

29. Park K, Tan EH, O’Byrne K, Zhang L, Boyer M, Mok T, et al. Afatinib versus gefitinib as first-line treatment of patients with EGFR mutationpositive non-small-cell lung cancer (LUX-Lung 7): a phase 2B, open-label, randomised controlled trial. Lancet Oncol (2016) 17(5):577-89. doi:10.1016/ S1470-2045(16)30033-X

30. Jänne PA, Ou S-HI, Kim D-W, Oxnard GR, Martins R, Kris MG, et al. Dacomitinib as first-line treatment in patients with clinically or molecularly selected advanced non-small-cell lung cancer: a multicentre, openlabel, phase 2 trial. Lancet Oncol (2014) 15(13):1433-41. doi:10.1016/ S1470-2045(14)70461-9

31. Kris MG, Camidge DR, Giaccone G, Hida T, Li BT, O'Connell J, et al. Targeting HER2 aberrations as actionable drivers in lung cancers: phase II trial of the pan-HER tyrosine kinase inhibitor dacomitinib in patients with HER2mutant or amplified tumors. Ann Oncol (2015) 26(7):1421-7. doi:10.1093/ annonc/mdv186

32. Mazieres J, Peters S, Lepage B, Cortot AB, Barlesi F, Beau-Faller M, et al. Lung cancer that harbors an HER2 mutation: epidemiologic characteristics and therapeutic perspectives. J Clin Oncol (2013) 31(16):1997-2003. doi:10.1200/ JCO.2012.45.6095

33. Chong CR, Jänne PA. The quest to overcome resistance to EGFR-targeted therapies in cancer. Nat Med (2013) 19(11):1389-400. doi:10.1038/nm.3388

34. Jänne PA, Yang JC-H, Kim D-W, Planchard D, Ohe Y, Ramalingam SS, et al. AZD9291 in EGFR inhibitor-resistant non-small-cell lung cancer. $N$ Engl J Med (2015) 372(18):1689-99. doi:10.1056/NEJMoa1411817

Conflict of Interest Statement: LP-A has received advisory honoraria from Roche, Lilly, MSD, Novartis, BMS, Clovis, Amgen, Boehringer Ing., Astra Zeneca, and Pfizer, not related to this work. The other authors declare that the research was conducted in the absence of any commercial or financial relationships that could be construed as a potential conflict of interest.

Copyright (® 2017 Zugazagoitia, Díaz, Jimenez, Nuñez, Iglesias, Ponce-Aix and Paz-Ares. This is an open-access article distributed under the terms of the Creative Commons Attribution License (CC BY). The use, distribution or reproduction in other forums is permitted, provided the original author(s) or licensor are credited and that the original publication in this journal is cited, in accordance with accepted academic practice. No use, distribution or reproduction is permitted which does not comply with these terms. 